\title{
A implantação da usina hidrelétrica do Baixo Iguaçu: uma análise a partir dos estudos em Ciência, Tecnologia e Sociedade
}

\author{
Catiane Matiello \\ Gilson Leandro Queluz
}

A implantação da usina hidrelétrica do Baixo Iguaçu: uma análise a partir dos estudos em Ciência, Tecnologia e Sociedade

Resumo: O artigo tem como objetivo analisar a implantação da usina hidrelétrica do Baixo Iguaçu, no Paraná, observando o conflito entre atingidos e empreendedores sob o marco teórico dos estudos em Ciência, Tecnologia e Sociedade. A partir da identificação das principais controvérsias entre os grupos em disputa, procurou-se compreender de que forma elementos fundamentais do projeto validam um determinado código técnico, conforme o conceito descrito por A. Feenberg. Foi observado que os argumentos empregados pelos grupos se alinham a determinadas frentes de interesses, articulando representações de tecnologia em padrões de legitimação sobre a implantação da hidrelétrica.

Palavras-Chave: UHE Baixo Iguaçu. Estudos CTS. Código técnico

The implantation of Baixo Iguaçu hydroelectric dam: an analysis from the Science, Technology and Society studies

Abstract: The aim of this article is to analyze the implantation of Baixo Iguaçu hydroelectric dam, in the Brazilian state of Paraná, taking account of the conflict between people affected by the dam and entrepreneurs in the theoretical framework of studies in Science, Technology and Society. Taking into consideration the implementation process of dams as a political arena, starting from the identification of the main controversies between the disputing groups, we sought to understand how fundamental design elements validate a particular technical code, according to the concept described by A. Feenberg. It was observed that the arguments employed by groups are aligned to certain interested fronts, articulating representations of technology in patterns of legitimacy on the implementation of the hydroelectric.

Key-Words: Baixo Iguaçu hydroelectric dam. STS studies. Technical code 


\section{Introdução}

O artigo tem como objetivo analisar a implantação da usina hidrelétrica do Baixo Iguaçu, no Paraná, observando o conflito entre atingidos e empreendedores sob o marco teórico dos estudos em Ciência, Tecnologia e Sociedade. A partir da identificação das principais controvérsias entre os grupos em disputa, procurou-se compreender de que forma elementos fundamentais do projeto validam um determinado código técnico, conforme o conceito descrito por A. Feenberg. Foi observado que os argumentos empregados pelos grupos se alinham a determinadas frentes de interesses, articulando representações de tecnologia em padrões de legitimação sobre a implantação da hidrelétrica.

A metodologia contou com uma viagem de caráter exploratório às cidades atingidas de Capitão Leônidas Marques e Capanema, onde a usina está sendo construída, e com pesquisa documental. Na pesquisa de campo houve a oportunidade de participar de reuniões entre atingidos, MAB, sindicatos de trabalhadores rurais, representantes de cooperativas, deputados e vereadores e representantes do consórcio Geração Céu Azul. Este contato inicial permitiu a produção de depoimentos, além de notas em caderno de campo. Os depoimentos produzidos resultaram de um trabalho de transcrição, textualização e transcriação ${ }^{1}$ dos registros em caderno de campo e áudio, a partir dos procedimentos da História Oral, conforme descritos por Meihy (2005) e Hollanda e Meihy (2007).

A pesquisa documental reuniu documentos como o Estudo de Impacto Ambiental (Eia) e o Relatório de Impacto Ambiental (Rima) da usina, atas das reuniões realizadas entre o consórcio Geração Céu Azul e a comissão de atingidos da barragem do Baixo Iguaçu, matérias jornalísticas, notas oficiais do MAB e do consórcio Geração Céu Azul e edições do Diário Oficial da Assembleia Legislativa do Paraná2.

Na documentação selecionada identificamos as principais controvérsias entre os grupos e exploramos os argumentos presentes, de modo a identificar como eles se alinham ou divergem em relação a determinadas frentes de interesses e quais as concepções de tecnologia presentes.

$\mathrm{O}$ artigo foi estruturado em quatro partes, além da introdução: na primeira, apresentamos o referencial teórico e analítico utilizado, com a definição dos conceitos utilizados. A segunda parte foi reservada à contextualização do projeto da usina, por meio da breve descrição de sua trajetória de desenvolvimento. A terceira parte é dedicada à apresentação e à análise das controvérsias. Encerramos com as considerações finais, retomando sinteticamente os pontos analisados e as conclusões parciais, relacionando-as ao papel dos processos de resistência no desenvolvimento tecnológico.

\footnotetext{
${ }^{1}$ Transcrição: passagem da narrativa para o texto escrito, operada pelo registro em caderno de campo e no registro em áudio. Todas as palavras faladas são registradas. Textualização: retiram-se os sons e ruídos. Palavras sem peso semântico também são extraídas e as perguntas do pesquisador são incorporadas à fala do entrevistado. O texto também é reorganizado de modo a criar uma narrativa coesa e agradável de ler. Transcriação: nela, procura-se reconstituir o momento da entrevista, interferindo no texto preenchendo vazios expressos na fala do entrevistado, de modo que o texto final revele emoções e o "tom" da entrevista 4) Autorização: foi solicitada uma leitura do texto para aprovação dos colaboradores (HOLANDA; MEIHY, 2007).

${ }^{2}$ SOCIEDADE DA ÁGUA CONSULTORIA AMBIENTAL LTDA, 2008a; SOCIEDADE DA ÁGUA CONSULTORIA AMBIENTAL LTDA, 2008b; COMISSÃO DE ATINGIDOS; NEOENERGIA/GERAÇÃO CÉU AZUL, 2013; ALEP, 2013a; ALEP, 2013b.
} 


\section{Referencial teórico e analítico}

O referencial teórico e analítico adotado orienta-se pelos preceitos do campo de estudos em Ciência, Tecnologia e Sociedade (CTS), que sustenta a crítica às noções de determinismo e de neutralidade da tecnologia e de linearidade e autonomia evolutiva do desenvolvimento tecnológico (CALLON, 1997; MARX, SMITH, 1996; PINCH, BIJKER, 1997).

É a partir dos conceitos desenvolvidos pelo filósofo A. Feenberg (2005), no seu diálogo com os pesquisadores vinculados à abordagem social-construtivista da tecnologia, que realizaremos a análise. Em sua "teoria crítica da tecnologia", este autor se preocupa em trazer a tradição da crítica filosófica às tendências sociais para o debate público sobre a tecnologia (FEENBERG, 2002).

Entre os conceitos importantes para a compreensão de sua teoria destacamos o de "código técnico". Um código técnico é "a realização tecnicamente coerente de um interesse numa solução a um problema" (FEENBERG, 2005, p. 8). Ele compreende que escolhas sociais intervêm nas decisões técnicas e que, portanto, enquanto construções sociais, estas não são neutras, nem somente determinadas ou determinadoras. Principalmente, o conceito discute a formulação tradicional que procura opor "eficiência técnica" e valores, considerando que "métodos ou padrões técnicos comuns já foram formulados discursivamente como valores e, em algum momento do passado, transformados nos códigos técnicos que hoje nos parecem evidentes" (FEENBERG, 2005, p. 8).

Outra noção importante discutida pelo autor corresponde a de "trocas compensatórias" (FEENBERG, 2007). Ela se baseia no princípio econômico de que a otimização de uma variável implica diretamente na redução de outra, o que resulta na orientação de que quanto maior a preocupação com os problemas ambientais, maior o sacrifício em termos de prosperidade e desenvolvimento ${ }^{3}$. Por essa lógica orientada pela relação custo/benefício, se a solução para resolver os problemas ambientais for abrir mão do conforto da modernidade e retornar a um modo de produção pré-industrial, deve-se questionar se o problema é, de fato, maior que a solução - raciocínio que se transforma no principal argumento de quem se opõem a uma "excessiva" regulação ambiental (FEENBERG, 2007).

A abordagem das trocas compensatórias no desenvolvimento da tecnologia pressupõe um antagonismo entre opções e, geralmente, quem fará a escolha entre elas é quem também as estabeleceu. Esse processo também acaba por estipular opções "ideológicas", "subjetivas", em oposição à alternativa "racional" e "eficiente".

Latente nessa lógica reside uma filosofia instrumentalista da tecnologia, elemento que também será alvo de questionamento na teoria crítica da tecnologia de Feenberg. Nela, a natureza é tratada como um conjunto de "materiais que esperam a transformação no que quer que desejemos” (FEENBERG, 2010a, p. 43). Feenberg

\footnotetext{
${ }^{3}$ Feenberg situa uma das origens deste tipo de raciocínio no campo ambientalista, no início de 1970, com a afirmativa de Paul Ehrlich de que a crise ambiental foi provocada pelo crescimento econômico e populacional e que, portanto, a sociedade deveria se "des-desenvolver", reduzindo o excesso de consumo (ver: EHRLICH, P. R.; HARRIMAN, R. L. How To Be a Survivor. New York: Ballantine, 1971).
} 
analisa esta visão, questionando o significado que o conceito de "eficiência" ganha no capitalismo:

Há uma tendência de desviar a crítica dos processos tecnológicos para os produtos e as pessoas, de uma prevenção a priori, para uma limpeza a posteriori. As estratégias preferidas são geralmente caras e reduzem a eficiência de uma determinada tecnologia. Tudo isso traz consequências políticas. Restabelecer o ambiente depois que ele foi afetado é uma forma de consumo coletivo, financiada por impostos ou preços mais altos. Tais enfoques dominam a consciência pública. É por isso que o movimento ambientalista é percebido como um custo que envolve trocas compensatórias (trade-offs) e não como uma racionalização que aumenta a eficiência como um todo (FEENBERG, 2010b, p. 82).

Para o autor, é das experiências e das necessidades dos indivíduos que resistem de diversas formas a uma hegemonia tecnológica específica, que podem emergir formas legais de iniciativa e participação. Utilizando o exemplo da regulamentação do trabalho infantil no século XIX, na Inglaterra, ele aponta a flexibilidade do sistema técnico, afirmando que ele pode adaptar-se a uma variedade de demandas sociais. Essa conclusão não deveria ser surpreendente, dada a capacidade de resposta da tecnologia à redefinição social, o que significa que a tecnologia é também uma variável social dependente (FEENBERG, 2010b, p. 75).

Quando as decisões que afetam nosso dia-a-dia são discutidas, a democracia política é inteiramente obscurecida pelo enorme poder exercido pelos senhores dos sistemas técnicos: líderes de corporações, militares e associações profissionais de grupos como médicos e engenheiros. Eles possuem muito mais controle sobre os padrões de crescimento urbano, o desenho das habitações, dos sistemas de transporte, a seleção das inovações, sobre nossa experiência como empregados, pacientes e consumidores do que o conjunto de todas as instituições governamentais da sociedade (FEENBERG, 2010b, p. 69).

Há que se considerar que a escolha de uma determinada tecnologia ocorre a partir de interesses entre muitas possíveis configurações e que, na orientação de seleção, estão códigos sociais estabelecidos pelas lutas culturais e políticas que definem o horizonte sob o qual a tecnologia atuará. Portanto, uma vez introduzida, a tecnologia oferece uma validação material do horizonte cultural para o qual foi pré-formada (FEENBERG, 2010b).

A partir dessas reflexões, das premissas que as orientam e das reflexões que estimulam é que analisaremos as práticas dos atores dentro do processo de desenvolvimento tecnológico.

\section{A usina hidrelétrica do Baixo Iguaçu}

A usina hidrelétrica do Baixo Iguaçu está sendo construída no rio Iguaçu, na região sudoeste paranaense, nas cidades de Capitão Leônidas Marques e Capanema. Ela será a sexta barragem, e última possível de ser construída, no principal rio do Estado. Seu reservatório, de 35,36 km2, comprometerá áreas dos municípios de Capanema, 
Realeza, Nova Prata do Iguaçu, Planalto e Capitão Leônidas Marques. O controle da usina está a cargo do consórcio Geração Céu Azul, formado pela Neoenergia (composta pelo Fundo de Pensão Previ, do Banco do Brasil e, majoritariamente, pela multinacional Iberdrola), que detém $70 \%$ de participação no empreendimento e pela Copel, que detém $30 \%$. Nos informativos sobre o empreendimento elaborados pela Neoenergia, destaca-se que a potência instalada, de 340 megawatts, será capaz de abastecer um milhão de pessoas (NEOENERGIA, s/d). No entanto, a afirmativa utilizada para legitimar a construção da obra é questionada pelo MAB (Movimento dos Atingidos por Barragens) com a informação de que $60 \%$ da energia gerada será destinada à Companhia Vale do Rio Doce para atividades de mineração (2013).

O primeiro projeto de uma hidrelétrica no Rio Iguaçu, nas proximidades do Parque Nacional do Iguaçu, é dos anos 1980. A então chamada usina de Capanema estava prevista no Plano Nacional de Energia (PNE) 1987/2010, com a capacidade de gerar 1,2 mil megawatts, inundando uma área de 80 quilômetros quadrados (MME; ELETROBRÁS, 1987; JASPER, 2012) e comprometendo parte da área do parque nacional. No entanto, o primeiro Plano Decenal de Expansão (PDE), concluído em 1989 e que abrangeu o período de 1990 a 1999, apresentou um quadro macroeconômico diferente do previsto no PNE, sugerindo um crescimento inferior ${ }^{4}$ e fazendo com que quarenta empreendimentos programados no PNE 1987/2010 fossem excluídos do Plano Decenal. Mas além das novas projeções de mercado e das restrições orçamentárias, de acordo com o relatório do plano decenal, o adiamento da construção de diversos desses empreendimentos também levou em consideração "restrições socioambientais do setor" (SOITO, 2011, p. 41). A contribuição estadual e regional às "restrições socioambientais" veio pela resistência de agricultores, cooperativas e políticos da região ${ }^{5}$. A ampla manifestação regional, contrária à usina, se impôs como um dos fatores relevantes na suspensão da sua implantação - o que viria a se refletir no seu desenho atual. Em novembro de 1984, o semanário "Nosso Tempo" noticiava:

A decisão foi tomada depois de intensa mobilização de lideranças do setor agrícola, de entidades preservacionistas, comerciais e industriais e de milhares de agricultores que saíram às ruas da cidade de Capanema, há pouco mais de um mês, numa contundente manifestação de protesto pelos graves problemas que seriam gerados com o alagamento de terras hoje ocupadas por milhares de minifúndios (NOSSO TEMPO, 1984, p. 14).

Em 2004, o projeto da barragem foi retomado com mudanças significativas em sua localização e de modo a reduzir a área alagada e a não interferir diretamente no Parque Nacional do Iguaçu. A Engevix Engenharia solicitou o licenciamento ao Instituto Ambiental do Paraná (IAP) e elaborou o primeiro Estudo de Impacto Ambiental e Relatório de Impacto Ambiental (EIA/RIMA). Desde então, uma disputa envolvendo a competência da obra se estabeleceu, considerando que o projeto comprometia uma área do Parque Nacional do Iguaçu, unidade de conservação sob

\footnotetext{
${ }^{4}$ Enquanto o PNE 1987/2010 indicava um crescimento médio anual do PIB em torno de 6,1\% de 1990 a 1995 e 5,8\% de 1995 a 2000 (MME; ELETROBRÁS, 1987; SOITO, 2011, p. 41), o plano decenal, por sua vez, previu um crescimento próximo de zero em 1990 e de 3\% em 1991 (SOITO, 2011, p. 41).

${ }^{5}$ Pinheiro e Sevá também atribuem a derrota do projeto da usina de Capanema a manifestações populares em 1983-1984 (2006, p. 11).
} 
gestão do IBAMA $^{6}$ (Instituto Brasileiro do Meio Ambiente e dos Recursos Naturais Renováveis) e sítio do Patrimônio Mundial Natural pela Unesco.

As obras da hidrelétrica, que deveria entrar em operação em 2013, começaram em julho de 2013, após a licença ambiental de operação do Instituto Ambiental do Paraná (IAP) ser emitida no mesmo mês. A implantação do canteiro de obras pela construtora Odebrecht, ocorreu com onze famílias residindo dentro do terreno destinado ao canteiro. Além disso, os atingidos denunciaram o grande número de famílias que não constam no cadastro realizado pela usina ${ }^{7}$, o valor das indenizações inferior ao preço de mercado, a não realização dos programas previstos no Plano Básico Ambiental e a ausência de propostas de áreas para reassentamento. A partir de então, ao longo de 2013, acirraram-se as práticas de resistência sob a organização da Associação dos Atingidos da Hidroelétrica do Baixo Iguaçu (ADAHBI) e, sobretudo, com a entrada em cena do MAB no auxílio à luta organizada das famílias.

Neste segundo momento da trajetória que define o projeto da barragem identificamos dois processos que têm importância na convergência de controvérsias sobre a usina e sobre as medidas adotadas com a população atingida: o processo de licenciamento ambiental, com as exigências de estudos e relatórios de impacto ambientais, e os debates entre deputados estaduais na Assembleia Legislativa do Estado do Paraná. Examinaremos ambos a seguir.

\section{Controvérsias sociotécnicas expostas: entre o licenciamento ambiental e a Assembleia Legislativa}

A resolução do CONAMA (Conselho Nacional do Meio Ambiente) 01/1986 (CONAMA, 1986) define que as usinas hidrelétricas estão sujeitas ao licenciamento ambiental e que para sua obtenção deverão apresentar ao órgão ambiental competente, o devido Estudo de Impacto Ambiental (EIA). O licenciamento é composto pelas etapas da licença prévia, licença de instalação e licença de operação, apresentadas pela resolução 237, de 1997. Estas etapas vinculam à determinadas fases do empreendimento a análise de viabilidade ambiental, cumprimento de condicionantes e fiscalização.

De acordo com Laschefski, Pereira e Zhouri (2005), historicamente, o licenciamento ambiental representa um avanço conquistado a partir dos debates, nos anos 1970 e 1980, em torno dos problemas causados pelas grandes obras. Ele é um dos principais instrumentos da Política Nacional de Meio Ambiente e deveria, além de garantir o cumprimento da legislação e das normas em vigor, possibilitar a participação da sociedade civil nas decisões sobre os grandes projetos, sobretudo através da Audiência Pública obrigatória.

No entanto, afirmam as autoras, afinado à noção capitalista de apropriação do meio ambiente, o processo acaba por perpetuar uma visão única sobre as formas de significar e utilizar os recursos naturais em detrimento de uma diversidade de modos de interação existentes. Sua natureza é mitigadora, pois ele restringe-se à reparação dos

\footnotetext{
${ }^{6}$ Em 2007, os setores do IBAMA responsáveis pela gestão das Unidades de Conservação foram separados, dando origem ao ICMBio (Instituto Chico Mendes de Conservação da Biodiversidade), criado pela Lei 11.516. Após isso o ICMBio passou a atuar no licenciamento.

${ }^{7}$ No pré-cadastro realizado pelo consórcio constam 360 famílias enquanto o MAB e a ADAHBI indicam cerca de 1000 famílias (MAB. Atingidos por Usina Hidrelétrica Baixo Iguaçu protestam na sede da Copel. 2013. Disponível em: <http://goo.gl/orrPLD>. Acesso em: $15 \mathrm{dez} 2013$ ).
} 
impactos sociais e ambientais, o que representa adotar como premissa, portanto, a concepção de que projetos hidrelétricos são viáveis, desde que aplicadas as medidas pontuais compensatórias (LASCHEFSKI; PEREIRA; ZHOURI, 2005, p. 36).

Seguindo as exigências do processo de licenciamento, o consórcio responsável pela construção da UHE do Baixo Iguaçu providenciou um Rima que também foi concebido sob essa visão mitigadora. Dele, selecionamos alguns trechos para análise:

A maior parte da energia produzida no Brasil é de origem hidrelétrica e essa opção, como já mencionado, foi fruto de condições econômicas, políticas e naturais do país, que possui um extraordinário potencial hídrico. Apesar desse potencial, o país, em 2001, enfrentou uma crise, chamada de "apagão", que resultou no racionamento de energia nas regiões Sudeste, Nordeste e Centro-Oeste. [...] Para afastar o risco de novos apagões, o país deverá investir maciçamente na produção de energia elétrica. [...] Essas fontes [alternativas] ainda não são capazes de produzir uma quantidade de energia suficiente para o atendimento de toda a demanda do país. Apresentam vantagens ambientais, embora estudos mais profundos sobre as mesmas, tenham revelado impactos importantes, principalmente no caso da energia eólica, que precisa de muito espaço e aumenta consideravelmente o risco de acidentes com animais. $\mathrm{O}$ custo dos equipamentos para geração dessas alternativas ainda é muito elevado e, na maioria das vezes, não compensam pelo que produzem (SOCIEDADE DA ÁGUA CONSULTORIA AMBIENTAL LTDA, 2008b, p. 31-33, grifo nosso).

O texto se preza a justificar a opção pelo investimento na construção da UHE do Baixo Iguaçu através de três argumentos: o "extraordinário potencial hídrico" ainda não explorado totalmente no país, a crise de energia que poderá desencadear um novo apagão e a impossibilidade de utilização de outras fontes de geração, seja pelos seus "impactos importantes", por seu custo muito elevado e pela relação entre custo/geração, que não compensariam os investimentos. Juntas, essas considerações compõem uma narrativa tecnológica ${ }^{8}$ que procura legitimar o investimento pelo critério de eficiência técnica.

A respeito do primeiro argumento, atribuir o largo emprego de hidreletricidade à oferta de potencial pela natureza, é algo que se pauta pela concepção instrumentalista da tecnologia, em que os rios estão à disposição do domínio tecnológico, por seu potencial de geração hidrelétrica. Já ao temor do apagão, opõem-se uma série de argumentos de especialistas que procuram demonstrar que a construção de novas UHEs é dispensável (BERMANN, 2003). Estes especialistas consideram desde folgas operacionais nas usinas já construídas e máquinas de reserva que podem ser acionadas até as previsões de consumo energético baseadas sempre em aumento de demanda.

No último argumento empregado no texto do RIMA, ao abordar as energias alternativas, surge de modo mais direto a lógica das trocas compensatórias, o que expõe

\footnotetext{
${ }^{8}$ Utilizamos o termo "narrativa" referindo-nos ao conceito de "narrativas tecnológicas", de David Nye: "Tecnologias são parte de um diálogo entre seres humanos sobre suas diferentes percepções. Este diálogo toma a forma de narrativas, diferentes histórias que contamos um ao outro para dar sentido às transformações que acompanham a adoção de novas máquinas [...]. Qualquer que seja a forma narrativa, as máquinas são raramente entendidas pelo público como coisas em si puramente abstratas. Ao contrário, as tecnologias funcionam como partes centrais dos dramáticos eventos" (NYE, 1997, p. 3).
} 
as contradições presentes nos critérios e coloca em cheque a presumida racionalidade técnica da eficiência. A informação de que as energias alternativas ainda não são capazes "de produzir uma quantidade de energia suficiente para o atendimento de toda a demanda do país" não é incontestável ${ }^{9}$. A tentativa de desqualificar as energias alternativas devido ao tamanho do espaço comprometido e ao risco de acidentes com animais é um argumento que perde o fundamento, quando vindo de uma indústria que compromete indelevelmente, com a submersão, habitats, comunidades, sítios arqueológicos e fluxos de rios. E é também o argumento que expõe os critérios para se estabelecer as opções entre as trocas compensatórias, afinal, importa menos uma alternativa com reduzido impacto ambiental, diante da possibilidade de maior lucro de seus empreendedores.

Sem considerar outro tipo possível de geração de energia ou outro padrão de consumo, portanto, são estabelecidos, de um lado, um horizonte de racionamento de energia, e de outro, energia à disposição, conquistada através da "eficiência técnica", mas às custas de danos ambientais e sociais. Um dos argumentos mais comuns na crítica a quem se opõe à construção das usinas hidrelétricas baseia-se justamente no questionamento sobre de onde virá a energia. Resta, então, apelar para medidas que "atenuem" os danos.

Assim, o RIMA da UHE do Baixo Iguaçu resolve os "impactos" através da listagem de 53 deles e de suas respectivas descrições e programas mitigadores. Dentre eles, listamos os que se vinculam de forma mais direta ao processo desapropriatório:

Quadro 1: Impactos ambientais

\begin{tabular}{|l|l|l|}
\hline \multicolumn{1}{|c|}{ Impactos } & \multicolumn{1}{|c|}{ Descrição } & \multicolumn{1}{|c|}{ Programas } \\
\hline $\begin{array}{l}\text { Comprometiment } \\
\text { o dos ambientes } \\
\text { físicos }\end{array}$ & $\begin{array}{l}\text { Com o início das obras ocorrerão escavações, construções de via } \\
\text { de acesso, movimentação de equipamentos e veículos de carga, } \\
\text { causando impactos como: ocorrência de poeira no ar, retirada da } \\
\text { camada fértil do solo, transporte de sedimentos e alteração da } \\
\text { qualidade da água no rio. }\end{array}$ & $\begin{array}{l}\text { Programtal da } \\
\text { construção; } \\
\text { programa de } \\
\text { educação } \\
\text { ambiental. }\end{array}$ \\
\hline $\begin{array}{l}\text { Formação de } \\
\text { expectativas } \\
\text { quanto aos efeitos } \\
\text { da implantação da } \\
\begin{array}{l}\text { UHE Baixo } \\
\text { Iguaçu }\end{array}\end{array}$ & $\begin{array}{l}\text { A notícia da implantação de um empreendimento como a UHE } \\
\text { sistema de preços, o mercado de trabalho, o mercado imobiliário e e } \\
\text { decisões dos agentes investidores. }\end{array}$ & $\begin{array}{l}\text { Programa de } \\
\text { comunicação } \\
\text { social e programa }\end{array}$ \\
\hline
\end{tabular}

${ }^{9}$ O Atlas Eólico Brasileiro, de 2001, refuta essa afirmação apresentando um potencial de energia eólica no Brasil de $143 \mathrm{GW}$. As medições dos ventos realizadas há mais de 10 anos registradas pelo atlas, consideraram torres eólicas de 50 metros de altura; a revisão dessas estimativas, considerando as atuais torres superiores a 100 metros, deve atualizar este potencial para mais de $300 \mathrm{GW}$, ou praticamente o triplo da capacidade instalada da matriz elétrica nacional. Isso, segundo Baitelo, ao segundo menor custo de geração de eletricidade, sem pesar os entraves técnicos e de mercado que dependem de vontade política (BAITELO, p. 67 apud BERMANN et al 2012). 


\begin{tabular}{|c|c|c|}
\hline $\begin{array}{l}\text { Mobilização e } \\
\text { engajamento } \\
\text { comunitário da } \\
\text { população local }\end{array}$ & $\begin{array}{l}\text { A implementação de uma barragem sempre estimula a população } \\
\text { local no sentido da mobilização política para discussão do } \\
\text { empreendimento, através da criação de instituições representativas } \\
\text { ou então pelo engajamento de agremiações já constituídas, como } \\
\text { sindicatos, associações comunitárias, organizações não- } \\
\text { governamentais, Ministério Público e Poder Público local. Esta } \\
\text { mobilização é um fato positivo, uma vez que intensifica a } \\
\text { discussão sobre o município, sua qualidade de vida e o manejo e } \\
\text { utilização dos recursos naturais existentes no território, } \\
\text { consistindo em momentos da vivência coletiva que certamente } \\
\text { contribuem para o fortalecimento do tecido social local, através do } \\
\text { reconhecimento das diferenças e enriquecimento do conhecimento } \\
\text { da realidade municipal e regional por parte da população } \\
\text { envolvida. }\end{array}$ & $\begin{array}{l}\text { Programa de } \\
\text { comunicação } \\
\text { social; programa } \\
\text { de educação } \\
\text { ambiental; } \\
\text { programa de } \\
\text { apoio à } \\
\text { elaboração das } \\
\text { Agendas } 21 \\
\text { locais. }\end{array}$ \\
\hline $\begin{array}{l}\text { Submersão de } \\
\text { áreas de lavoura e } \\
\text { pastagem }\end{array}$ & $\begin{array}{l}\text { O enchimento do reservatório acarretará em perdas de áreas de } \\
\text { pastagens e lavouras que serão permanentemente inundadas. }\end{array}$ & $\begin{array}{l}\text { Programa de } \\
\text { apoio aos } \\
\text { municípios e } \\
\text { comunidades } \\
\text { locais; programa } \\
\text { de } \\
\text { remanejamento } \\
\text { da população } \\
\text { atingida e } \\
\text { programa de } \\
\text { desenvolvimento } \\
\text { turístico. }\end{array}$ \\
\hline
\end{tabular}

Fonte: SOCIEDADE DA ÁGUA CONSULTORIA AMBIENTAL LTDA, 2008b, p. 69-73.

Outra narrativa baseada na noção de trocas compensatórias, mas agora envolvendo a concepção do novo projeto da hidrelétrica do Baixo Iguaçu, está em um artigo científico publicado por engenheiros da Engevix, no XXVI Seminário Nacional de Grandes Barragens, realizado em 2005. O foco aqui, portanto, não é mais a opção pela hidreletricidade, mas as opções de projeto no trecho em questão do Rio Iguaçu:

Embora do ponto de vista energético-econômico, o aproveitamento de Capanema seja vantajoso, em função da regularização proporcionada pelos reservatórios de montante e por aproveitar na totalidade a queda disponível do rio lguaçu, a sociedade tem demonstrado estar disposta a arcar com as consequiências do não aproveitamento de parte da queda disponível para preservar seus bens naturais mais relevantes (PEREIRA et al, 2005, p. 3, grifo nosso).

E concluem:

Uma alternativa de 1.200 MW, ambientalmente inviável, foi reavaliada para uma de $340 \mathrm{MW}$, ambientalmente possível e economicamente atrativa. Evidentemente, sobre a ótica energética, 
perdeu-se potência. Contudo, atualmente não impera somente a visão de um único setor, como acontecia antigamente com o setor elétrico. Hoje em dia, a visão integrada do sistema dificulta que um setor se sobreponha sobre o outro e com isso, todas as interfaces devem ser consideradas. Dentro desta nova ótica, os efeitos sobre o meio ambiente para esta nova partição de queda podem ser considerados aceitáveis pela sociedade e ainda assim, competitivo (sic) do ponto de vista econômico-energético (PEREIRA et al, 2005, p. 8, grifo nosso).

O que os engenheiros chamam de "visão integrada" surge como interferência dos valores na eficiência. Cabe à sociedade "arcar com as consequências do não aproveitamento de parte da queda disponível", além de aceitar determinados "efeitos sobre o meio ambiente", definidos a priori, em uma disputa da qual provavelmente não fez parte.

Dessa forma, pensar essas narrativas em termos de trocas compensatórias explicita a adoção de uma concepção tecnológica que assume dois princípios: o determinismo tecnológico, pois na opção entre desenvolvimento e padrões préindustriais, afirma-se o sistema industrial atual como único possível; e o princípio da neutralidade da tecnologia, pois uma vez que a tecnologia deverá ser julgada apenas pela sua eficiência, ela acaba sendo vista como desprovida de valores.

Diante das práticas do consórcio e de um processo de licenciamento que não garantiu os direitos da população atingida, surgem as contra-narrativas e os processos de resistência dos grupos que se sentem prejudicados. Na reunião de negociação entre os atingidos e representantes da Neoenergia que acompanhamos, no dia 24 de outubro de 2013, o agricultor Éder Pichette, cuja terra atingida situa-se dentro do canteiro de obras da usina fez uma intervenção. Sua fala começou tratando de uma oferta de indenização realizada pela empresa no dia anterior, que havia sido considerada ofensiva pelo agricultor, e logo ganhou o tom de desabafo:

A gente se sente desrespeitado. É o dia inteiro sem sossego e a noite inteira sem dormir, porque tem detonação tremendo a nossa casa... $\mathrm{E}$ isso, na realidade, é um problema de imposição! A gente tá com a corda no pescoço! [...] vocês estão brincando com a gente! Vamos ver a questão das reuniões: é reunião, reunião, reunião e reunião. E não se toma decisão. Só fica no "diz que-diz que". Todas as autoridades tão aqui! Alguém tem que resolver isso! Essa obra tá andando! Concordam comigo que a obra tá andando? E o cidadão, o agricultor, que tira o sustento da terra, pra sobrevivência, tá lá, esperando a desapropriação. [...] Vamos fazer o desenvolvimento? Vamos fazer! Vamos fazer a obra? Vamos! Então vamos fazer o paredão de concreto, vamos fazer a energia, pois isso é essencial pro país, com certeza! Mas antes de tudo, as pessoas têm que ser respeitadas. [...] Tem que ter um acordo com o cidadão, mas parece que pra vocês esse acordo tem que ser feito para o desenvolvimento e não para o ser humano. [...] E o problema do reassentamento? O reassentamento é uma coisa... é como um sonho! Pra que todas aquelas famílias ali tivessem uma terra. É um sonho, mas é o mínimo que tinha que fazer. E mesmo assim não adiantaria porque a gente tem uma história ali naquele local, sabe? A gente se criou ali... a gente é de família muito pobre, sabe? A gente pegava até empreitada do vizinho pra ganhar pão, porque na seca a gente não tinha o sustento... [...] e tem ainda os 
problemas fora da obra: vão montar casa de prostituição onde era lavoura! E as famílias? E as crianças? As crianças vão olhar pra todos esses problemas! Como é que as crianças vão se criar assim, no meio de um povo assim? (Fala de Éder Pichette, registrada em caderno de campo e áudio em 24/10/2013).

O agricultor sintetizou os principais problemas que se repetem na implantação de barragens e expôs a tensão estabelecida entre aqueles que administram a tecnologia e os que são submetidos a ela. Éder fala da exclusão da participação no processo de definição, da compensação financeira pelas perdas materiais, do surgimento da prostituição no entorno do canteiro de obras, das práticas dos consórcios durante a construção da barragem e das estratégias de negociação. Tratam-se de consequências desconsideradas ou minimizadas no Rima, o que ocorre a partir de uma linguagem técnica que racionaliza, divide, organiza e indica formas de solução aparentemente simples.

O mesmo padrão se verifica nos debates sobre a usina, realizados na Assembleia Legislativa do Paraná, onde as concepções determinadoras e neutras de tecnologia, a visão conformista acerca do desenvolvimento, a lógica de trocas compensatórias baseia as argumentações. O discurso a seguir, do Deputado Estadual Rasca Rodrigues (Partido Verde), compõe uma das peças mais exemplares das noções a que nos referimos:

Porque uma represa não pode ser indesejada; um espelho d'água como esse não pode ser indesejado, ele tem que ser amado pela população, mas desde que ela use, porque quem usa, cuida. Quero dizer que tem um impacto, sim, e o impacto é significativo, apesar de ser considerada uma represa quase em fio d'água, mas que, neste momento por que o País passa, a necessidade que temos de energia, acho que esse custo pode ser absorvido em relação à questão ambiental, porque vai trazer um grande desenvolvimento para a região (ALEP, 2013a).

O projeto de construção da UHE do Baixo Iguaçu foi debatido pelos deputados que o aprovaram sem nenhum voto contrário sob o projeto número 142/2013, em 7 de maio de 2013 (ALEP, 2013a). Paralelamente às discussões que levaram a aprovação do projeto, ocorreu a proposição, por parte da bancada do Partido dos Trabalhadores, de uma emenda que previa que a usina só pudesse começar a ser construída a partir do momento em que todas as famílias fossem indenizadas: "O início da construção das usinas a que se refere o presente projeto de lei, fica condicionado à efetiva indenização de todos os atingidos, bem como o atendimento das condicionantes legais aplicáveis à espécie" (ALEP, 2013a, p. 9). A emenda não foi aprovada sob o argumento de que, certamente, a usina só seria instalada após todos os agricultores terem sido indenizados ${ }^{10}$.

Assim, diante das violações de direitos relacionadas ao descumprimento das medidas mitigadoras exigidas no processo de licenciamento, previstas no RIMA e discutidas pelos deputados na Assembleia Legislativa, cerca de 350 agricultores

10 “Infelizmente, essa emenda não passou nesta Casa, não tivemos votos suficientes, porque a resposta dada aqui neste Plenário é que, com certeza, a usina só iria começar a partir do momento em que os agricultores fossem indenizados" (ALEP, 2013b, p. 7). 
atingidos, organizados pela Comissão de Atingidos, MAB e CPT, ocuparam o canteiro de obras da usina e paralisaram as obras no dia 09 de setembro de 2013. Seu objetivo era exigir avanço no termo de acordo firmado em audiência pública no dia 16 de agosto de 2013. Pela ocupação, o MAB recebeu um Interdito Proibitório expedido pela juíza do município de Capanema, estabelecendo uma multa diária de $\mathrm{R} \$ 100.000,00$ caso os manifestantes praticassem qualquer ato de "turbação ou esbulho na posse da empresa". A manobra do consórcio resultou na assinatura de um termo em que os atingidos se comprometeram a não realizar mais nenhuma ocupação do canteiro no período de 30 dias, ao que o consórcio responderia com a suspensão do interdito proibitório.

Desde então, cerca de cinco reuniões ocorreram entre atingidos, MAB e consórcio até a reunião que acompanhamos. Seis meses depois, no dia 20 de novembro de 2013, os agricultores atingidos vieram do interior do Paraná para exigirem da Copel agilidade nas negociações e pedir apoio dos deputados para que atuassem junto ao Governo do Estado na solicitação de auxílio para um acordo com o consórcio (ALEP, 2013b). Hélio Meca, representante do MAB, subiu na plenária e fez o seguinte discurso:

Mas gostaria de dizer, em especial aos Deputados e as Deputadas que estão aqui, que ser atingido por uma barragem é a mesma coisa que você ser assaltado por bandidos à mão armada, ser estrangulado, vedarem a tua boca, amarrarem e te fecharem num banheiro, e só com reza você pode se desamarrar e se libertar. (...) Dizer aos Deputados que é uma coisa que quase não conseguimos acreditar, porque a Aneel, que é um órgão federal, concede a barragem. Como aqui, o Governo do Estado do Paraná autoriza, apoia, a Assembleia Legislativa apoia a barragem, o IAP dá a licença e consegue legalizar a obra, e depois, quando não se cumpre as devidas licenças e quando não se faz aquilo que deveria ser feito pelos atingidos por barragens, praticamente esses órgãos desaparecem e deixam o povo atingido a ver navios. [...] Parece, por boca de alguém, que os atingidos querem ficar ricos com a construção da Usina do Baixo Iguaçu. Não é verdade. As pessoas estão pedindo apenas para ser reposto aquilo que vão perder. E com certeza, se é para ficar igual, como estão hoje, não queremos a barragem, porque a barragem só foi aceita na região em nome do desenvolvimento regional, em nome do progresso do povo que mora ali, em nome do desenvolvimento e a melhoria das condições de vida. (...) precisamos fazer um acordo antecipado: primeiro o homem, depois o cimento (ALEP, 2013b, p. 7).

O discurso de Hélio Meca contextualiza a situação dos atingidos estabelecendo a responsabilidade dos atores e distinguindo-os na trajetória da usina, vinculando-os aos mecanismos que limitam a participação da população diretamente atingida no processo. Chama atenção em sua fala a subversão da acusação que ouvimos algumas vezes na reunião que acompanhamos, e que corresponde à ideia de que os atingidos querem "se aproveitar" do consórcio para "melhorar de vida". Como afirma Hélio Meca, se o discurso que legitima a construção da usina fala em desenvolvimento e melhorias para a população, por que motivo, exatamente, a indenização e o reassentamento não podem representar isso para os atingidos?

Sua proposta colocada em forma de uma metáfora em que os projetos devem considerar "primeiro o homem, depois o cimento" conforma a subversão do arranjo 
técnico atual, que privilegia alguns aspectos do ser humano e marginaliza outros. Este arranjo orquestrado pela assimetria de poder técnico entre empreendedores e atingidos, reflete-se no sentimento de impotência de Éder e dos outros agricultores diante da dinâmica de negociações e do aparato legal e político que sustenta a implantação de um grande projeto como este.

\section{Considerações finais}

As controvérsias observadas entre os principais grupos sociais observados corresponderam à participação no processo decisório, à efetivação de direitos dos atingidos, às práticas da empresa e à desconsideração de valores imateriais e subjetivos dos atingidos. Verificamos que a noção de desenvolvimento que orienta o projeto é pautada pela visão de trocas compensatórias, que coloca a consideração de fatores ambientais e sociais como um custo que entrava o desenvolvimento. Esta visão, junto ao que há de implícito nela, conforma o código técnico da UHE e se reflete na forma com que a população atingida é tratada pelo consórcio.

$\mathrm{O}$ conceito de código técnico nos auxiliou ao identificar o licenciamento ambiental como um instrumento de gestão construído no âmbito de disputas políticas e econômicas. Enquanto resultado da incorporação de valores, ele também passa a ser instrumentalizado por determinados grupos, desempenhando destacado papel no exercício do poder técnico. Este, por sua vez, produz resistências dos que são excluídos do processo de design tecnológico e daqueles que percebem as consequências indesejáveis das tecnologias.

Nesse sentido, queremos destacar que os protestos da comunidade regional, nos anos 1980, pesam enquanto critério ambiental e social em nível federal e conquistam a suspensão do projeto, mesmo sem o marco regulatório de que dispomos atualmente. Essa conquista, que teve como um de seus principais argumentos o comprometimento de área do Parque Nacional do Iguaçu, passa a compor o código técnico do novo projeto da usina, nos anos 2000. Este, já elaborado no contexto de um marco regulatório ambiental e após um processo de privatização do setor elétrico, condensa a opção por um projeto de menor capacidade de geração, que reduz os "entraves" ambientais e sociais e facilita sua concretização.

Entendemos que os processos de resistência desafiam o horizonte da racionalidade sob a qual a tecnologia é projetada, de forma que critérios sociais e ambientais passam a não ser considerados como entraves, mas como elementos que aumentam a eficiência tecnológica em termos mais amplos. Pensar este processo em termos de código técnico revela os valores e os interesses dos atores fixados nas regras e procedimentos que conduzem aos instrumentos e artefatos, que por sua vez, os validarão. Queremos acreditar, como propõe a teoria crítica, que os cálculos entre custos/benefícios que regem a definição de controvérsias na implantação de usinas têm sua aplicação em situações transitórias, antes que avanços tecnológicos, respondendo a novos valores sociais, alterem os termos fundamentais do problema. 


\section{Referências}

ALEP. Diário Oficial da Assembleia. Edição no 421, Publicação no 63. Curitiba: 10 mai. 2013a.

ALEP. Diário Oficial da Assembleia. Edição no 553, Publicação no 195. Curitiba: 25 nov. 2013b.

BERMANN, C.; MILLIKAN, B.; FEARNSIDE, P. (orgs.). O Setor Elétrico Brasileiro e a Sustentabilidade no Século 21: Oportunidades e Desafios. Brasília: Rios Internacionais, 2012.

CALLON, M. Society in the making: the study of technology as a tool for sociological analysis. In: BIJKER, Wiebe E. et al (eds.). The social construction of technological systems: new directions in the sociology and history of technology. Cambridge, Mass.: MIT Press, 1997, p. 83-103.

COMISSÃO DE ATINGIDOS; NEOENERGIA/GERAÇÃo CÉU AZUL. Ata. Capitão Leônidas Marques, Paraná: Prefeitura Municipal de Capitão Leônidas Marques, 24 de outubro de 2013.

CONAMA. Resolução no 237, 19 dez. 1997. Diário Oficial da República Federativa do Brasil, Poder Executivo, Brasília, 1997. Disponível em: 〈http://goo.gl/37ZHa〉. Acesso em: 20 jan. 2014.

CONAMA. Resolução ${ }^{\circ}$ 001, 23 jan. 1986. Diário Oficial da República Federativa do Brasil, Poder Executivo, Brasília, 1986. Disponível em: <http://goo.gl/r2Zec〉. Acesso em: 21 jan. 2014.

FEENBERG, A. Between Reason and Experience: Essays in Technology and Modernity. Cambridge, MA: MIT Press, 2010a.

FEENBERG, A. Incommensurable Paradigms: Values and the Environment. Revue du MAUSS, 6 ago 2007. Disponível em: 〈http://goo.gl/BZJp7Q〉. Acesso em: 07 out. 2013.

FEENBERG, A. Racionalização Subversiva: Tecnologia, Poder e Democracia. In: NEDER, R. T. A Teoria Crítica de Andrew Feenberg: Racionalização Democrática, Poder e Tecnologia. Brasília: Observatório do Movimento pela Tecnologia Social na América Latina / CDS / UnB / Capes, 2010b, p. 67-97.

FEENBERG, A. Teoria crítica da tecnologia. Trad.: Equipe de Tradutores do Colóquio Internacional "Teoria Crítica e Educação". São Paulo: Unimep, Ufscar, Unesp, 2005. Disponível em: <http://www.sfu.ca/ andrewf/>. Acesso em: 20 set. 2013. FEENBERG, A. Transforming technology. A critical theory revisited. New York: Oxford University Press, 2002.

HOLANDA, F.; MEIHY, J. C. S. B. História Oral: como fazer, como pensar. São Paulo: Contexto, 2007.

JASPER, F. Usina de Baixo Iguaçu, ainda no papel. Gazeta do Povo. Curitiba, 14 jul. 2012. Disponível em: <http://goo.gl/ut3VNk>. Acesso em: 28 out. 2013.

LASCHEFSKI, K.; PEREIRA, D.; ZHOURI, A. (orgs.). A Insustentável leveza da Política Ambiental. Desenvolvimento e Conflitos Socioambientais. Belo Horizonte: Autêntica, 2005.

MAB. Atingidos mantém ocupação na UHE Baixo Iguaçu. Disponível em: <http://goo.gl/dgci7J>. Acesso em: 19 dez. 2013.

MARX, L. - SMITH, M. R. Does technology drive history? The dilemma of technological determinism. Cambridge, Mass: MIT Press, 1996. 
MEIHY, J. C. S. B. Manual de História Oral. São Paulo: Edições Loyola, 2005.

MME; ELETROBRÁS. Plano Nacional de Energia 1987/2010. Rio de Janeiro, dez. 1987. Disponível em: <http://goo.gl/WwOfDH〉. Acesso em: 07 jan. 2014.

NOSSO TEMPO. Movimento comunitário frustrou construção de nova usina no rio Iguaçu. Foz do Iguaçu, 2 nov. 1984. ed. 143, p. 14. Disponível em: < http://www.nossotempodigital.com.br/edicao/143/ >. Acesso em: 13 fev. 2014.

NEOENERGIA. UHE Baixo Iguaçu. s/d. Disponível em: 〈http://goo.gl/2s0wH2>. Acesso em: 19 dez. 2013.

NYE, D. Constructing Nature: Niagara Falls and the Grand Cayon. In: NYE, David. Narratives and spaces: technology and the construction of american culture. New York: Cambridge University Press, 1997. p. 01-43

PEREIRA, G. M. et al. Revisão do inventário do rio Iguaçu - Minimização das interferências ambientais com o Parque Nacional do Iguaçu. In: XXVI Seminário Nacional de Grandes Barragens. Goiânia, 2005. Disponível em: <http://goo.gl/8I0yQw>. Acesso em: 8 jan. 2014.

PINCH, T.; BIJKER, W. E. The social construction of facts and artifacts: or how the Sociology of Science and the Sociology of Technology might benefit each other. In: BIJKER, Wiebe E. et al (eds.). The social construction of technological systems: new directions in the sociology and history of technology. Cambridge, Mass.: MIT Press, 1997, p. 17-50.

PINHEIRO, M. F. B.; SEVÁ FILHO, O. A. Expansão Hidrelétrica no Período 20032006: Conflitos Sociais e Institucionais em Novas Represas e nas Concessões Leiloadas. In: III Encontro da ANPPAS. Brasília/DF, 2006. Disponível em: <http://goo.gl/dildnc>. Acesso em: 16 jan. 2014.

SOCIEDADE DA ÁGUA CONSULTORIA AMBIENTAL LTDA. UHE Baixo Iguaçu - Estudo de Impacto Ambiental (EIA). Curitiba: abr. 2008a.

SOCIEDADE DA ÁGUA CONSULTORIA AMBIENTAL LTDA. UHE Baixo Iguaçu - Relatório de Impacto Ambiental (RIMA). Curitiba: abr. 2008b.

SOITO, J. L. da S. Amazônia e a expansão da hidroeletricidade: vulnerabilidades, impactos e desafios. 2011. 403 f. Tese. COPPE, UFRJ, Rio de Janeiro, 2011. 